Blyth, H., and Pugh, R. (1959): Muscular Dystrophy in Childhood. The Genetic Aspect. Annals of Human Genetics, 23, 127.

Dent, C. E., and Harris, H. (1956): Hereditary Forms of Rickets and Osteomalacia. Journal of Bone and Joint Surgery, 38-B, 204.

IDELBERGER, K. (1939): Die Ergebnisse der Zwillingsforschung beim angeborenen Klumpfuss. Verhandlungen der Deutschen Orthopädischen Gesellschaft, 33, 272.

IDELBERGER, K. (1951): Die Erbpathologie der sogenannten angeborenen Hüftverrenkung. Munich: Urban und Schwarzenberg.

Linneroth, K., Hallgren, B., Palmen, J., and Zetterström, R. (1958): Primary (Genuine) Vitamin D Resistant Rickets. Acta Paediatrica, 47, 568.

Maroteaux, P., Lamy, M., and Bernard, J. (1957): La dysplasie spondylo-epiphysaire tardive. Presse Médicale, $65,1,205$.

MORCH, E. T. (1941): Chondrodystrophic Dwarfs in Denmark. Copenhagen: Ejnar Munksgaard.

Stevenson, A. C. (1953): Muscular Dystrophy in Northern Ireland. Annals of Eugenics, 18, 50.

Stevenson, A. C. (1957): Achondroplasia: an Account of the Condition in Northern Ireland. American Journal of Human Genetics, 9, 81 .

\title{
NEUROPATHIC JOINTS
}

Charcot's original paper of 1868 , " On some arthropathies which appear to depend on a lesion of the brain or spinal cord," described two forms of joint lesions associated with disease of the nervous system.

The first was that occurring in the course of locomotor ataxia giving rise to swelling, usually of the knee joint, of sudden onset, in the absence of fever, redness and pain, and accompanying excessive mobility of the joint. The second affected the joints of paralysed limbs in hemiplegia of cerebral origin, and was accompanied by severe pain on movement with redness, swelling and warmth of the affected joints. Only the former retains the eponym Charcot's joint. As the years passed, similar joint changes were found in other diseases; for example, syringomyelia, affecting especially the elbow and shoulder; diabetes mellitus, especially in the ankle and foot, though here both ischaemia and infection played a part; and many other spinal cord, posterior root and peripheral nerve lesions which resulted in analgesia, and often in loss of proprioception. For all of these many modern authors use the generic term neuropathic joint.

Charcot held the view that the joint changes resulted from a removal of the "trophic" influence of the nervous system over bones and joints, but this was challenged by Westphal (1881) with the strong support of Volkmann (1882), and later of Rotter (1887). Volkmann related the destruction of the joint to repeated trauma which, owing to the analgesia, was unperceived, and owing to the loss of proprioception was unmitigated when the joint was exposed to extreme movements; hence repeated damage to the joint resulted in the classical clinical and radiological picture (Cohen 1955).

Volkmann's view of the pathogenesis of a Charcot's joint received strong support from the experimental work of Eloesser (1917) confirmed by Delano (1946). Eloesser showed that a Charcot joint in cats, although it may rarely follow simple section of the posterior nerve roots, consistently follows that operation if concomitant joint injury is inflicted. Subsequent observations in man (Casagrande, Austin and Indeck 1951) have tended to confirm that not only must there be loss of pain, but also proprioceptive loss and continued use of the joint.

In recent years two conditions have been added to the list of causes of Charcot's joint. First is the fascinating condition of congenital universal indifference to pain, of which van der Houwen describes an example in this issue of the Journal. Secondly, there is the arthropathy following intra-articular corticosteroid therapy.

VOL. 43 B, NO. 2, MAY 1961 


\section{CONGENITAL UNIVERSAL INDIFFERENCE TO PAIN}

In 1938 Ford and Wilkins described three children between the ages of seven and nine who could not recognise any painful stimulus. This was a condition that had to be distinguished from the absence of reaction to pain which is occasionally seen, for example, in hysteria, hypnosis and those depressive psychoses in which self mutilation is not uncommon. It is, of course, within most people's experience that in extreme excitement, anger or fear, as in combat or sport, they may not feel pain or react to it.

In true congenital indifference to pain there are several criteria. First, the condition dates from birth or early life and is permanent. Jewesbury's report (1951) of a boy who at sixteen months appeared grossly indifferent to pain but was normal at two and a half years should be excluded from this group. Secondly, analgesia is found throughout the whole body, and to all forms of painful stimuli-prick, pinch, burn, intense cold, faradic shock, etc.; and the normal physiological phenomena that accompany pain, such as changes in pulse rate and blood pressure, are absent. Accompanying slight defects for other forms of sensation have occasionally been described, but there is never any gross sensory loss except for pain.

In a few patients evidence of mental subnormality and other neurological defects have been noted, but in most there is normal or accelerated intellectual development. This adds weight to the view that we are dealing with "insensitivity" and not "indifference " to pain.

The condition is brought to light by incidents which unmask this insensitivity to pain, such as bruises, cuts, burns or dental extractions; so it is not surprising that many patients with congenital indifference to pain have presented with bone or joint lesions. These include fractures, bone atrophy, osteomyelitis, joint luxation and arthropathies of the Charcot type, such as that which van der Houwen describes.

One of the most striking of these patients has been the subject of four reports in the literature, including that by Petrie (1953), who described the orthopaedic complications of this patient, and Feindel (1953), who examined specimens of skin, fascia, periosteum, bone and cartilage, and found nerve fibres in all. He concluded from his examination that "from the histological evidence available, it seems probable that the defect in perception of pain, and in the reflex productive effects of pain in this subject lies in central rather than in peripheral nerve structures." Since van der Houwen wrote his paper this patient has died, and a full account of her history and necropsy has been published by Baxter and Olszewski (1960). They carried out a complete examination of the nervous system but " failed to demonstrate any anatomical abnormality of those nervous system structures thought to be concerned with the transmission, elaboration and perception of pain impulses," though they could not " exclude the possibility that the defect is actually an anatomical one, either submicroscopic or in terms of organisation rather than structure."

\section{INTRA-ARTICULAR CORTISONE}

The method of treating an arthritic joint by intra-articular injections of cortisone was introduced by Hollander in 1951. Ten years later he was able to report his experience and that of his colleagues of 100,000 injections in 4,000 patients, and claimed that instability of a weight-bearing joint occurred in only thirty-seven joints in twenty-six patients $(0.7 \mathrm{per}$ cent). In four joints, however, there was an extensive absorption of bone associated with aseptic necrosis, and though they claimed that there was no loss of sensation or proprioception in these unstable joints, they did speak of them as " relatively painless."

Other authors have reported rapid deterioration of joints, especially of the osteoarthritic hip, after repeated hydrocortisone injections, leading to a picture which is clinically and radiologically indistinguishable from a Charcot joint (Chandler, Jones, Wright and Hartfall 1959).

Two factors in pathogenesis are clearly: 1) the relief of pain which corticosteroids give; and 2) the consequent greater mobility and use of the joint with increasing damage. A third 
factor is almost certainly the softening of bone which high concentrations of corticosteroids produce in their neighbourhood, greater than, but akin to, the osteoporosis which often follows corticosteroids by mouth.

It is clearly imperative that careful radiological supervision should control intra-articular therapy with corticosteroids.

The story of Charcot's joints illustrates three stages in the evolution of our knowledge of any clinical phenomenon. In the first it is regarded as a pathognomic sign of the disease in which it was described. Later it is found to occur in other diseases, sometimes of known cause. Finally its pathogenesis is understood in terms of dysfunction for which an anatomical substratum might be revealed. It is only at this final stage that we can claim to understand why in newly described diseases old signs reappear.

COHEN OF BIRKENHEAD.

\section{REFERENCES}

Baxter, D. W., and Olszewski, J. (1960): Congenital Universal Insensitivity to Pain. Brain, 83, 381.

Casagrande, P. A., Austin, B. P., and Indeck, W. (1951): Denervation of the Ankle Joint. Journal of Bone and Joint Surgery, 33-A, 723.

Chandler, G. N., Jones, D. T., Wright, V., and Hartfall, S. J. (1959): Charcot's Arthropathy Following Intra-articular Hydrocortisone. British Medical Journal, i, 952.

Charcot, J. M. (1868): Sur quelques arthropathies qui paraissent dépendre d'une lésion du cerveau ou de la moëlle épinière. Archives de Physiologie Normale et Pathologique, I, 161, 379.

Conen, Sir Henry (1955): In Textbook of the Rheumatic Diseases. Edited by W. S. C. Copeman. Second edition, p. 282. Edinburgh and London: E. \& S. Livingstone Ltd.

Delano, P. J. (1946): The Pathogenesis of Charcot's Joints. American Journal of Roentgenology, 56, 189.

Eloesser, L. (1917): On the Nature of Neuropathic Affections of the Joints. Annals of Surgery, 66, 201.

FEINDEL. W. (1953): Note on the Nerve Endings in a Subject with Arthropathy and Congenital Absence of Pain. Journal of Bone and Joint Surgery, 35-B, 402.

FORD, F. R., and WILkINS, L. (1938): Congenital Universal Insensitiveness to Pain. Johns Hopkins Hospital Bulletin, 62, 448.

Hollander, J. L., Brown, E. M., Jun., Jessar, R. A., and Brown, C. Y. (1951): Hydrocortisone and Cortisone Injected into Arthritic Joints. Journal of the American Medical Association, 147, 1629.

Hollander, J. L., Jessar, R. A., and Brown, E. M., Jun. (1961): Intra-synovial Corticosteroid Therapy: a Decade of Use. Bulletin on Rheumatic Diseases 11, No. 5.

Jewesbury, E. C. O. (1951): Insensitivity to Pain. Brain, 74, 336.

Petrie, J. G. (1953): A Case of Progressive Joint Disorders Caused by Insensitivity to Pain. Journal of Bone and Joint Surgery, 35-B, 399.

Rotter, J. (1887): Die Arthropathien bei Tabiden. Archiv für Klinische Chirurgie, 36, 1.

VolkmanN, R. von (1882): Comment on Westphal's paper. Zentralblatt für Chirurgie, 9, 174.

WestPhal, C. (1881): Gelenkerkrankungen bei Tabes. Berliner Klinische Wochenschrift, 18, 413. 